\title{
US costs and outcomes associated with Clostridium difficile infections: a systematic literature review, meta-analysis, and mathematical model
}

\author{
ML Schweizer ${ }^{1 *}$, R Nelson², M Samore ${ }^{2}$, S Nelson², K Khader ${ }^{2}$, H-Y Chiang ${ }^{1}$, M Chorazy ${ }^{3}$, L Herwaldt ${ }^{1}$, D Diekema ${ }^{1}$, \\ A Blevins $^{4}$, M Ward $^{1}$, E Perencevich ${ }^{1}$
}

From 3rd International Conference on Prevention and Infection Control (ICPIC 2015)

Geneva, Switzerland. 16-19 June 2015

\section{Introduction}

An understanding of the health and economic impact of C. difficile infections (CDI) can inform investments in prevention and treatment interventions.

\section{Objectives}

To estimate the burden of CDI in the US using a metaanalysis and economic model.

\section{Methods}

We searched PubMed, CINAHL, EMBASE and others for multicenter studies published in the US between 20002014 that evaluated CDI outcomes or costs. Studies were included in the economic analysis if they measured postinfection costs, post-infection length of stay (LOS), or propensity score-matched CDI patients to non-CDI controls. We also included studies that evaluated CDI-associated mortality with a control group. We created an economic model using TreeAgePro 2014.

\section{Results}

When the 22 studies that evaluated mortality were pooled, CDI was associated with a 2.5 -fold increase in mortality compared with other hospitalized patients (pooled RR=2.54; 95\% CI: 1.89, 3.40). Only 4 low $/ \mathrm{mod}$ erate quality studies evaluated costs of CDI. The mean CDI-attributable cost of the index hospitalization ranged from $\$ 8,426$ to $\$ 48,500$. The mean costs per CDI after discharge were $\$ 1,592$ for outpatient visits and $\$ 14,847$ for readmissions. When these values were adjusted to 2013 US dollars and included in the economic model,

${ }^{1}$ Internal Medicine, University of lowa, lowa City, IA, USA

Full list of author information is available at the end of the article we found that the mean total cost of a CDI was $\$ 32,198$ ( $\mathrm{SD}=\$ 9,798)$. Of the 3 studies that evaluated LOS using propensity matching, the mean CDI-attributable LOS was 12.3 days. When this excess LOS was multiplied by an average cost per day from a private $3^{\text {rd }}$ party payer perspective, CDI cost an average of $\$ 56,663$ (SD = $\$ 19,804)$.

\section{Conclusion}

Pooled estimates from the currently available literature suggest that CDI is associated with large health and economic burdens. However, the majority of available studies were of moderate/low quality and may overestimate the outcomes. Thus, these estimates should be used with caution and higher-quality studies should be completed to guide future economic evaluations of CDI prevention and treatment interventions.

\section{Disclosure of interest}

None declared.

\section{Authors' details}

${ }^{1}$ Internal Medicine, University of lowa, lowa City, IA, USA. ${ }^{2}$ Internal Medicine, University of Utah, Salt Lake City, UT, USA. ${ }^{3}$ Epidemiology, University of lowa, lowa City, IA, USA. ${ }^{4}$ Library Sciences, University of lowa, lowa City, IA, USA.

Published: 16 June 2015

doi:10.1186/2047-2994-4-S1-037

Cite this article as: Schweizer et al: US costs and outcomes associated with Clostridium difficile infections: a systematic literature review, metaanalysis, and mathematical model. Antimicrobial Resistance and Infection Control 2015 4(Suppl 1):037.
Ciomed Central

(c) 2015 Schweizer et al; licensee BioMed Central Ltd. This is an Open Access article distributed under the terms of the Creative Commons Attribution License (http://creativecommons.org/licenses/by/4.0), which permits unrestricted use, distribution, and reproduction in any medium, provided the original work is properly cited. The Creative Commons Public Domain Dedication waiver (http://creativecommons.org/publicdomain/zero/1.0/) applies to the data made available in this article, unless otherwise stated. 